\title{
A Four-Step Process to Studying the Field through the City of London
}

\section{i. Introduction}

This paper proposes a four-step process to studying the field that, in unpacking the field of finance and the City of London, offers a theoretical and methodological resource of Bourdieu's field analysis. Connecting physical space to social space, the field stands as a 'deliberately constructed', 'abstract representation' of a social space that offers a 'bird's eye view' of the multiple relationships which take place within its boundaries (Bourdieu, 1984, p. 165). The task of identifying and exploring the field is, as Harquinet et al. (2012) argue, concerned with how social relations are positioned within a spatial metaphor that leads to a conceptual vision of a social reality. Developing on this, this paper presents a visual construction of a social space through which it is possible to draw attention to the embedded and legitimised assumptions, common rule systems and day-to-day practices that sustain a dominating construction of social, cultural and material life. While this methodological approach is orientated in relation to a ruling field of finance, this should be read as a recourse that can be developed, adapted and applied to other competing fields across society. In the context of urban analysis, the spatial metaphor of the field lends itself directly to not just mapping a conceptual visualisation of a social space but also enables the researcher to both explore and evaluate the underlying and hidden framework of action that constructs and shapes social experience. However, as Swartz (1997, p. 4) argues, the concept of the field - unlike Bourdieu's other key concepts of cultural capital and habitus - has been given relatively little attention and remains under theorised. This is despite the field remaining crucial to a fuller understanding of cultural experience and practice in the way that it conceptualises relations between culture and social structure. Nonetheless, undertaking a field analysis is crucial to analysing the complex matrix of social and material interaction, embodied power relations and institutional hierarchies that are played out in a relatively autonomous arena for struggle and distinction. 
To explore the social field and its competing interests is to better understand the cultural construction of physical and social space that can be used to critically evaluate an embedded system of practice. In Sack's (1999) terms, this speaks directly to a critical analysis of a dominant and self-perpetuating version of reality. Breaking this position down, this paper offers four layers of analysis through which it is possible to understand and evaluate the competing relational positions that are at play in a given social field:

1. To address the construction and maintenance of the field's boundary that establishes the terms of engagement and, crucially, consecrates a dominant biography of success.

2. To establish and explore the arenas of legitimation that exists at the heart of the social field that relates to the institutions and social sights that preserve a hierarchy of exclusivity.

3. To chart the mechanisms and tools of development that both sustains and reproduces a distinct social reality.

4. Finally, to situate this social reality within a broader, 'horizontal' field of power that presses on all social fields.

These steps form the main structure of this paper, using the City of London to outline an overarching picture to explore a culturally embedded system of situated action and meaning making which produces practice, shapes meanings and constructions social structures - all of which helps better understand the practices, inherent struggles and forms of legitimation that characterise a given social field. From this, what emerges is a deeper understanding of how the field of financial life establishes a social regime of competition in which economic actors engage in struggle for domination or recognition by reproducing the homologous effects of market based distinction. 


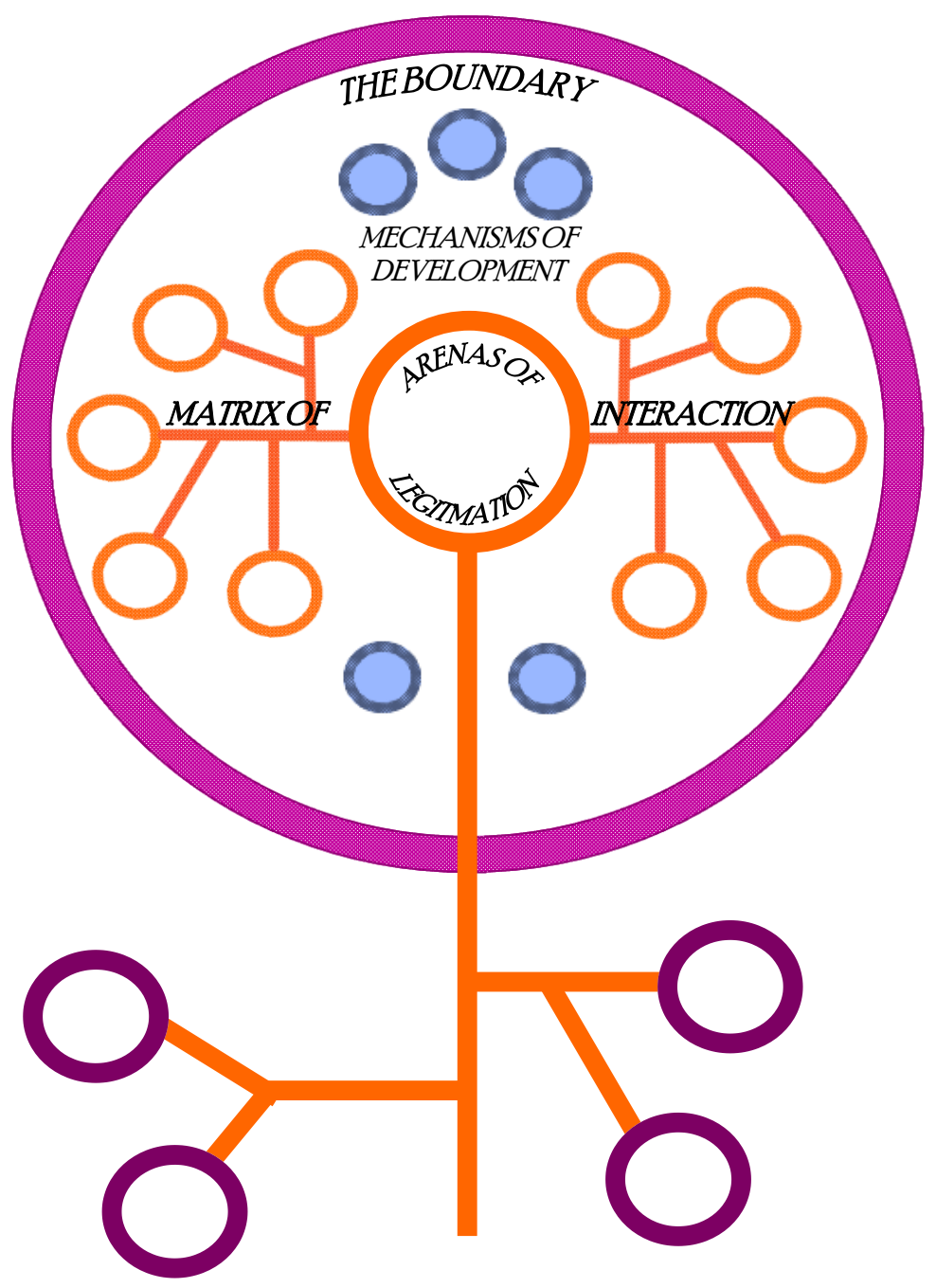

Opposed to Goffman's 'total institutions' or Foucault's orders of 'discipline', Bourdieu's field analysis is a framework characterised by competitive struggle for resources, resistance and domination that serves to both monopolise and legitimise the exercise of symbolic violence and competition (Bourdieu \& Wacquant, 1992; Swartz, 1997). In the context of urban analysis, this is intrinsically related to the social formation of place. As a structured space, organised around specific types and combinations of capital, the field represents a 'network' or 'configuration' of objective relations between positions (Bourdieu \& Wacquant, 1992, p. 97). In this context, Bourdieu's (1984, p. 22) 'relational' mode of thinking constructs a 'space of positions' that live 'external to one another' as well as being 'defined' by their 'relative distance' to produce a hierarchical and stratified system of domination. Through cultural resources, symbols and practices, social actors embody the interests and functions of the 
cultural field to enhance their own social distinction and, at the same time, produce a structuring power of symbolic violence played out through a system of capital (Bourdieu, 1977). The result is the production of a situated and version of reality that exists both inside and outside of individuals, through the minds, bodies and the material structure pressed onto the cultural formation of the field.

Each overlapping field of interest, such as the field of finance, operates within a 'meta field' that operates as an organising principle of differentiation and struggle throughout all fields (Bourdieu \& Wacquant, 1992). This is, in part, played out in the way the social field represents conceptually and physically the relational power struggles that are marked on the urban landscape (Harquinet, et al., 2012). In relation to the construction of place, the territorial rules and constitutive understandings that establish meaning and practice within a given setting, or place, defines the concept of resident, guest, stranger or citizen (Sack, 1993). Within each field, actors engage in a competitive struggle for domination or recognition to unwittingly reproduce the homologous effects of the social structure that, in turn, engender a unifying habitus of strategies, constraints and opportunities (Bourdieu, 1991). In the context of the City of London and the field of finance, recruitment, socialisation and organisational structure come to uphold the market bestowed ideology of action as a dialectic of action and reproduction. Within this, economic actors engage in the competitive struggle for domination or recognition by reproducing the homologous effects of the social class structure. This, in turn, engenders a unifying habitus of strategies, constraints and opportunities. As an outcome, Smithsimon (2010) argues that the very structural orientation of place produces action and generates meanings that determine every day empirical reality.

The role of the researcher within this framework of analysis is to begin to reveal the integrating logic of competition that sustains action and creates conflict, before relating this to the broader field of power and, finally, identifying shared assumptions and practices. In this context of this study, this 
meant incorporating a three-tiered ethnographic approach that drew on in-depth interviews, nonparticipant observation and photographic representation. This process of data collection focused on gaining access to public and institutional sites of social interaction, whilst purposively targeting front office economic actors, such as traders, investment bankers, brokers and sales managers. Led by direct interactions in the field, the process of non-participant observation aimed to study people in their naturally occurring setting so to capture their social meanings and ordinary activities (Brewer, 2000). Targeting key institutional and social sites within the City of London and Canary Wharf, this process enabled a deeper engagement with the situated practices of economic actors within the social and material world to shed light on the symbolic practices and interactions of social life. Alongside this, photographic representation offered a visual description of these social processes and the routines of daily experience by capturing a visual representation of a social space which leads to an enhanced, sensory understanding of the field (O'Reilly, 2005). Finally, in the form of a 'conversation with a purpose' (Webb \& Webb, 1932, p. 130), qualitative research interviews sought to elicit descriptions, explanations and evaluations of the meanings individuals attribute to their experience; a process which speaks directly to the individualised disposition. 


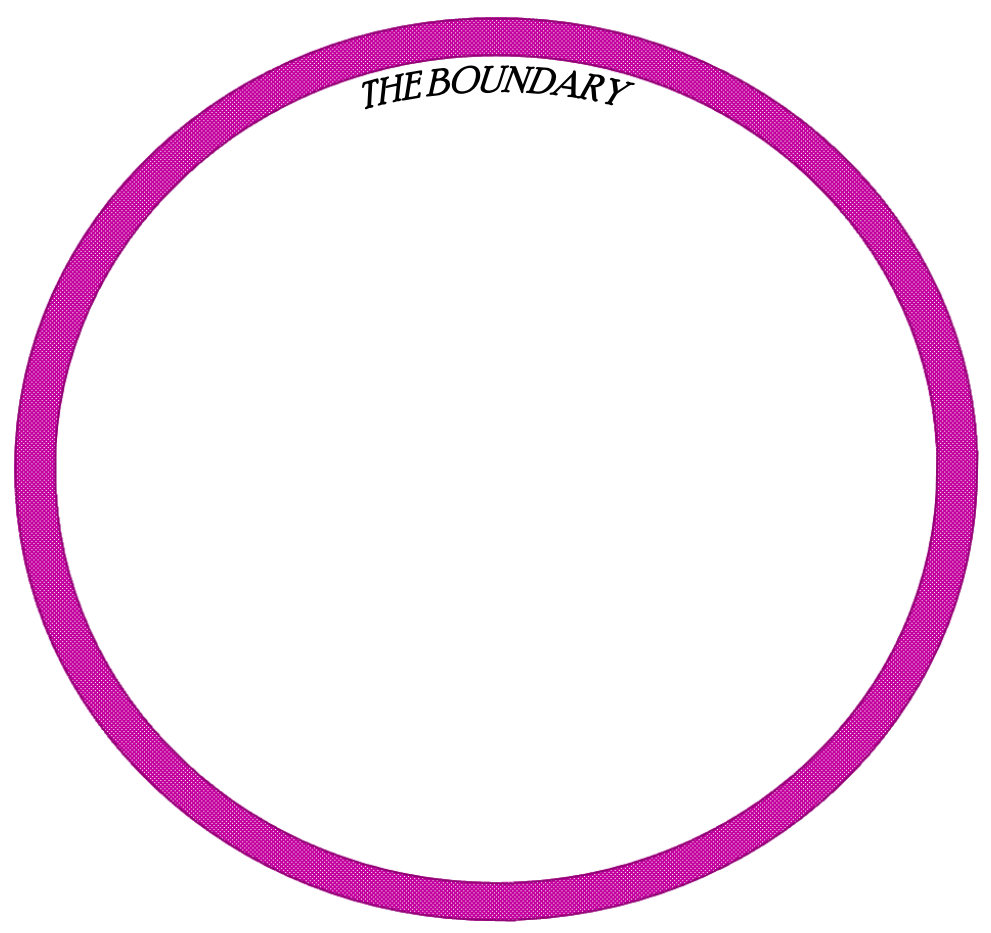

The first step in outlining a visual conception of the field begins with demarcating the boundary of action. For Bourdieu (1977), this is not a straightforward endeavour since any effort to establish a precise boundary between fields derives from a 'positivist vision' rather than a 'relational' view of the social world. Boundaries are themselves objects of struggle and resistance that, through a process of inclusion and exclusion, will impinge on the nature of investigation; however, refusing to establish a boundary leaves the concept of the field excessively generous in application (Swartz, 1997). The field of finance, in an era of global deregulation and hyper capital mobility, is often characterised by a weightless, impersonal and disembodied allure (Helleiner, 2011; Pauly, 2011). Therefore, it may be possible to argue that the field of financial life is equally 'weightless', 'impersonal' and 'disembodied' in its makeup. Yet, against this picture of abstract technologisation there remains a physical, spatial setting in which the financial markets remain overwhelmingly rooted (Cetina \& Bruegger, 2002). These are spaces where people meet face-to-face through formal work-based channels and opportunities as well as at informal spaces outside of the work place (Cetina \& Bruegger, 2002; Sassen, 2005). In line 


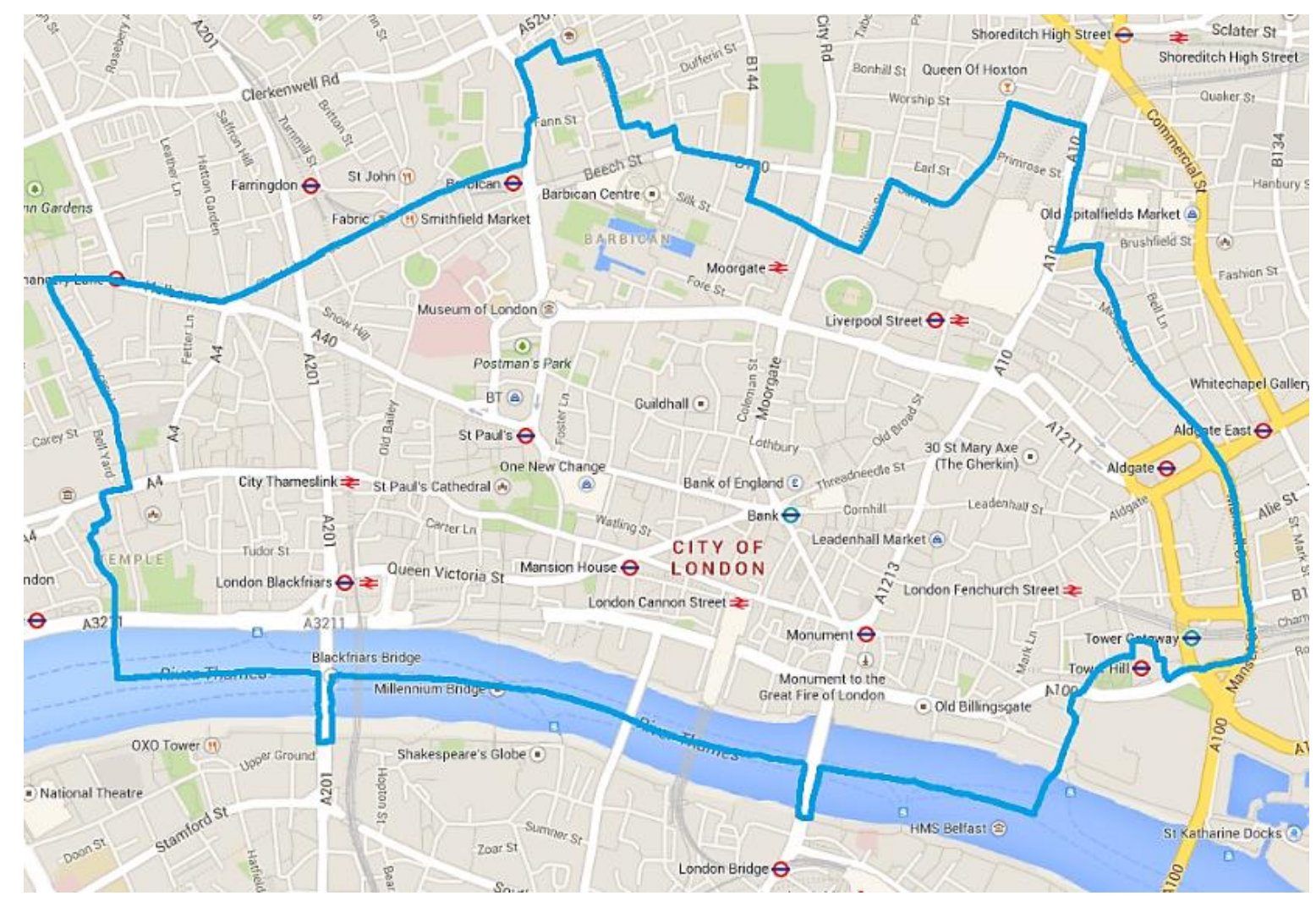

Figure 1: The geographical boundary of the City of London

with this, the task of identifying the field is, in this instance, intrinsically linked to the $1.22 \mathrm{~m}^{2}$ area that sits on the north bank of the Thames (see Figure 1). Focusing primarily on front of house, market and client facing positions, the City of London incorporates all institutions and agents who engage in the 'formal' banking sector and its relational form stretches to incorporate the City's tributary to the east, Canary Wharf. However, it deliberately excludes the largely unregulated and informal 'shadow banking' collective of hedge funds and maturity investment centres that are located primarily to the west in Mayfair. Together, these two principal spaces of market action sit alongside other global financial centres such as New York, Tokyo and Hong Kong to form a key financial hub in the global market system.

Within the field's boundary, it is important to draw attention to the material and social systems of symbolic dominance that establishes the unifying terms of engagement. In relation to the field of finance, the entire architectural and physical construction of the City is defined by the collective 


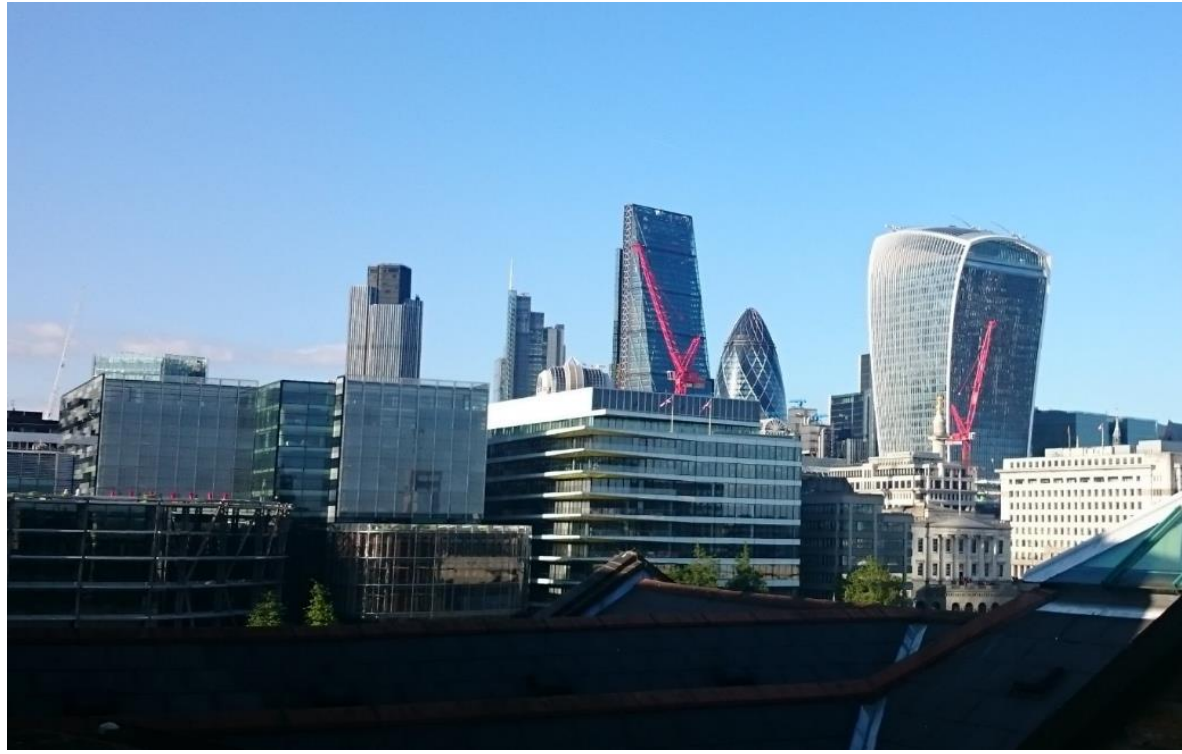

Figure 2: Skyline of the City of London wealth and success

that the financial

services industry

generates. As the

material manifestation

of the power, privilege

and wealth of the

market system, the

skyline is dominated by

a new clutch of

architectural landmarks that have risen out of the on-going, post-millennium financial boom. The inherent position of the City in relation to the speed and flow of the market mechanism means that its wealth and prominence is etched into the topographical landscape. The iconic buildings of finance, as shown in Figures 2 and 3, dominate the landscape and stand as physical manifestations of the City's cultural and economic position of power at the heart of the global marketplace. Standing beneath these bourgeoning structures, their long shadows loom over the tightly knitted collection of lanes and alleys to create an overall enclosed and claustrophobic feeling. For the City workers who pass through the streets on a daily basis, the scale and grandeur of these buildings is a

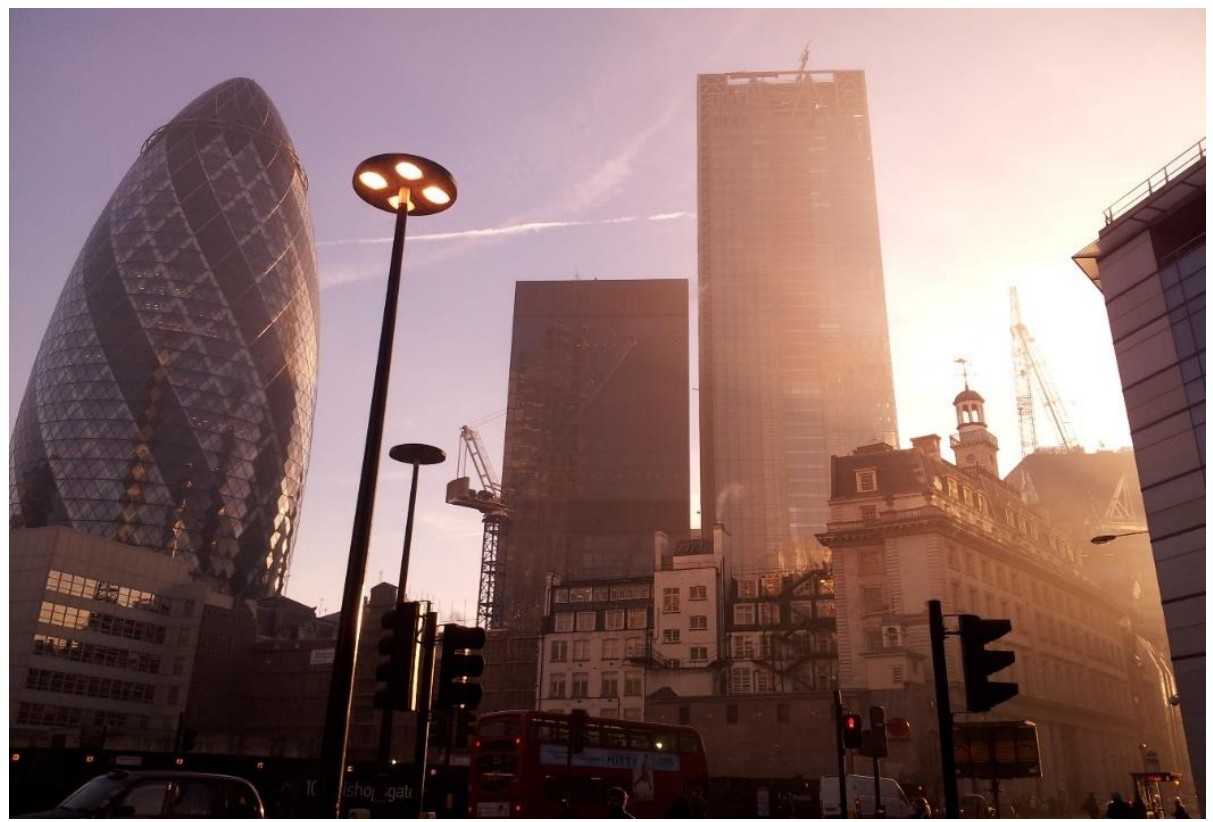
reminder of who 
delivers and is responsible for this collective wealth and success. As a coherent structure of 'oneness', 'wholeness' and 'greatness', these vast steel and glass structures invoke images of renaissance cathedrals as well as serve, in the manner of Wacquant and Bourdieu (1993), as a 'great reservoir of symbolic power' of the power and ubiquity of the market mechanism.

This symbolic display of wealth and power comes together through the minds, bodies and material surroundings of the City to generate a cultural formation of practice organised around the pursuit of profit and the strategic display of authority. As the material manifestation of market dominance, the

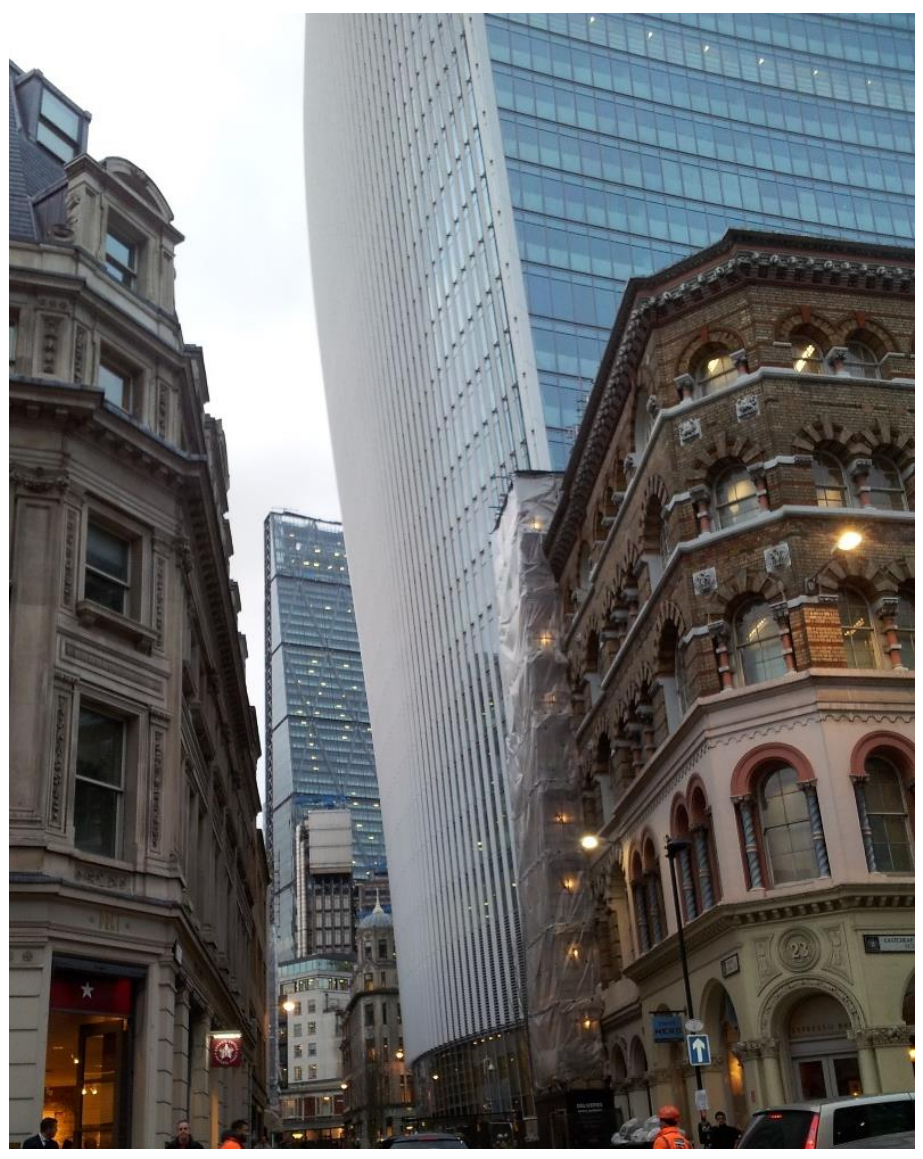

Figure 4: The 'Walkie Talkie' taken from Eastcheap Street importance of these physical constructions are a reminder that social reality exists not just within the minds of actors, but is also etched onto the material structure of society around us (Bourdieu, 1980). The rich tapestry of financial wealth serves as a stark reminder of the organisation of power and its relation to capital. Perpetually pressed and shaped in an orchestrated manner over time, the historical layers within the City, as made evident in Figure 4 , establish a common framework of truth, justice and morality embedded within the taken for granted market mechanism (Sack, 1999; Therborn, 2013). The prominence of the City emerged out of the mercantile exchange networks established in the time of Elizabeth I, with its current form being shaped by the slow victories of capital mobility over regulatory restraint that took 
place throughout the 1960s and the eventual abolition of exchange controls in 1979. Its tributary, Canary Wharf, is a product of the increased demand and influx of foreign investment when, in 1986, the London stock markets were opened up to foreign investment firms in 1986 (Helleiner, 2011; Kynaston, 2002; Shaxson, 2011). Today, just short of 400,000 people converge within the City of London to, in their own capacity, bring to life an embodied system of market action (ONS, 2014). Of this number, about 160,000 actively work within the financial services industry and, as part of their day to day experience, interact with this surrounding topographical, technological and social environment to actively (re)produce a culturally embedded and dominant system of market behaviour.

Within this spatial metaphor, there exists a rank and hierarchy as well as an exchange of relations between dominant and suburbanite social groups who compete for distinction and cultural legitimation (Bourdieu, 1977). As a symbol of legitimate domination, institutions and agents alike collectively adhere to the market and its monopoly of power as a symbolic definition of the capital that reproduces the inherent structure of the field. Nowhere is this more evidenced than in the maintenance of the field's periphery, demarcating in both a relational and physical sense one experiential world from another. Standing at the corner of Bishopsgate and Worship Street on the north eastern corner of the City, through Figure 5 it is possible to look inwards to the vast if undistinguished complex of Royal Bank of Scotland buildings and the ubiquitous 'Gherkin' that line the streets to form a corridor of wealth and prominence. However, to the left of the picture is the other side of the City's boundary. Here, the line of contrasting red brick warehouse buildings that remain 


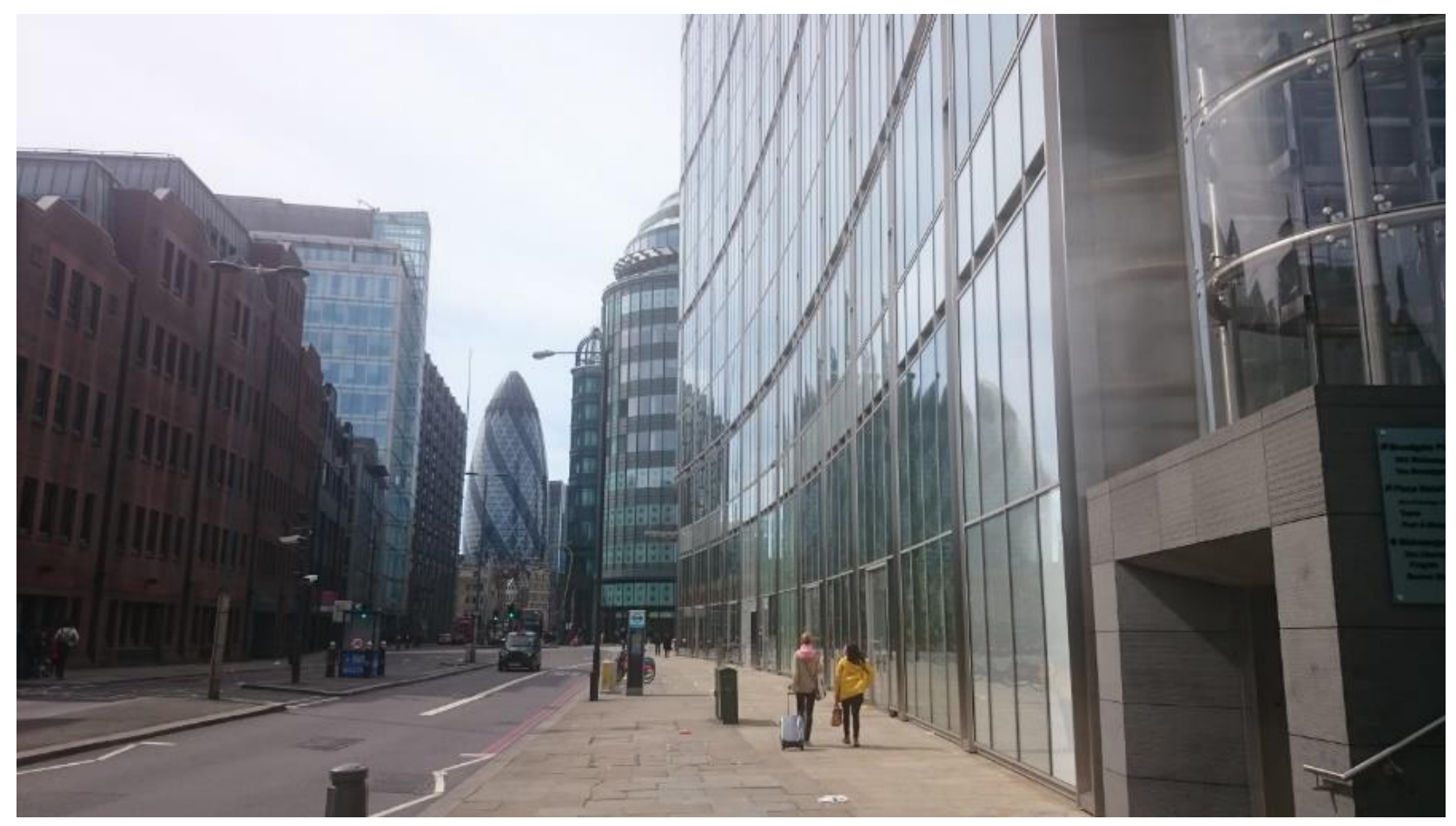

Figure 5: The City's boundary at Bishopsgate

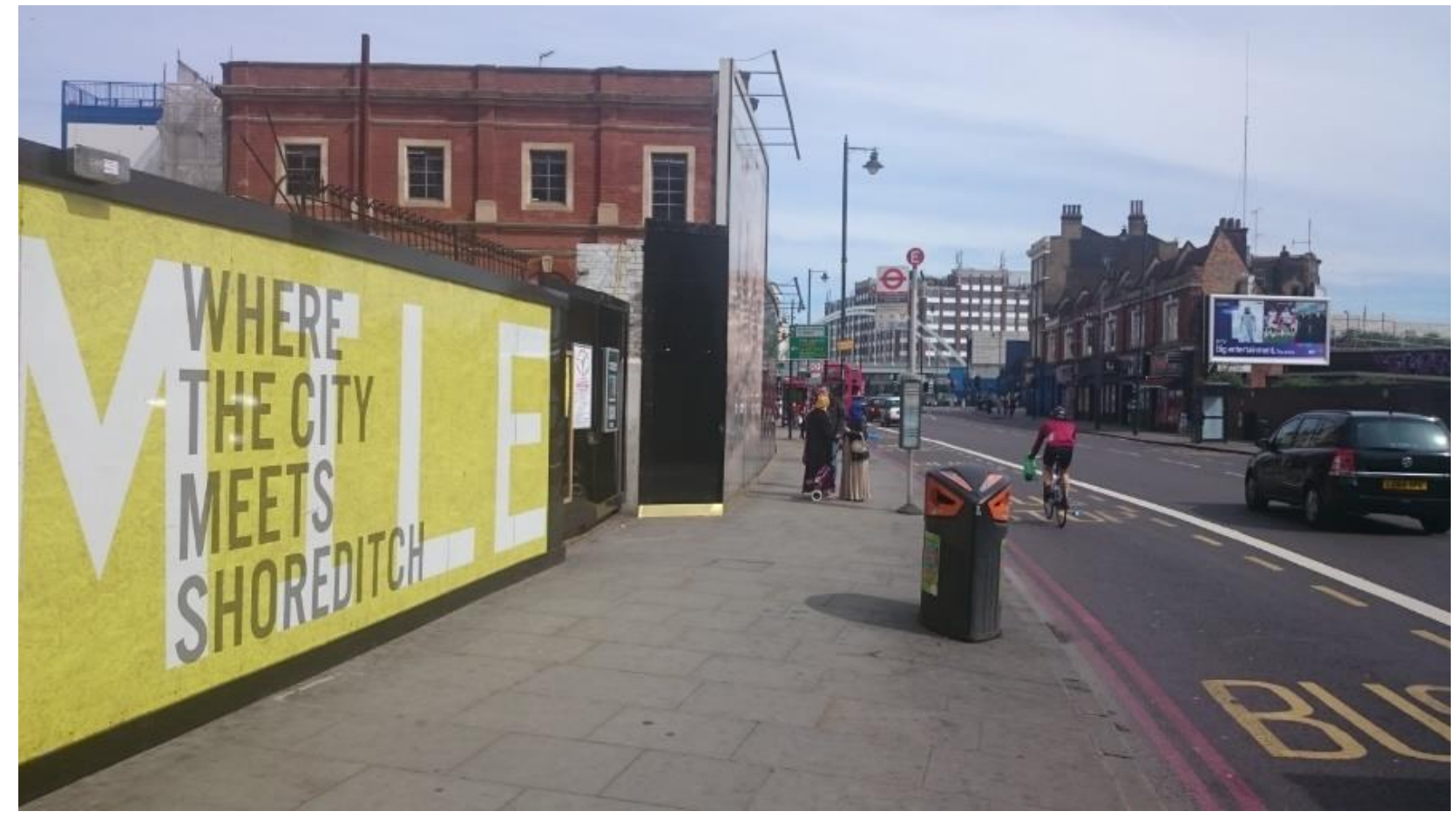

Figure 6: Looking the other way towards Shoreditch

untouched by financial development and the encroachment of the clutches of market wealth. Turning 180 degrees to face the other way, towards Shoreditch, Figure 5 shows a very different landscape. The steel and glass of financial institutions are replaced by post-war concrete. Historic facades are 
blackened with underfunding and the cranes that loom over the rising City skyline remain conspicuous in their absence. Similar, if not more striking, observations can be made with relation to the bounding of Canary Wharf, marshalled by their own private security to prevent unwanted encroachment, from the touch and deprived area of Millwall in which it is situated. The geographical boundary of the City provides a useful line that demarcates experience, presenting a framework of conceptual and spatial analysis to better explore a distinct financial 'way of life' as well as a dominant and legitimate vision of a situated social.

iv. Struggle and Legitimation: The structural control of the bank

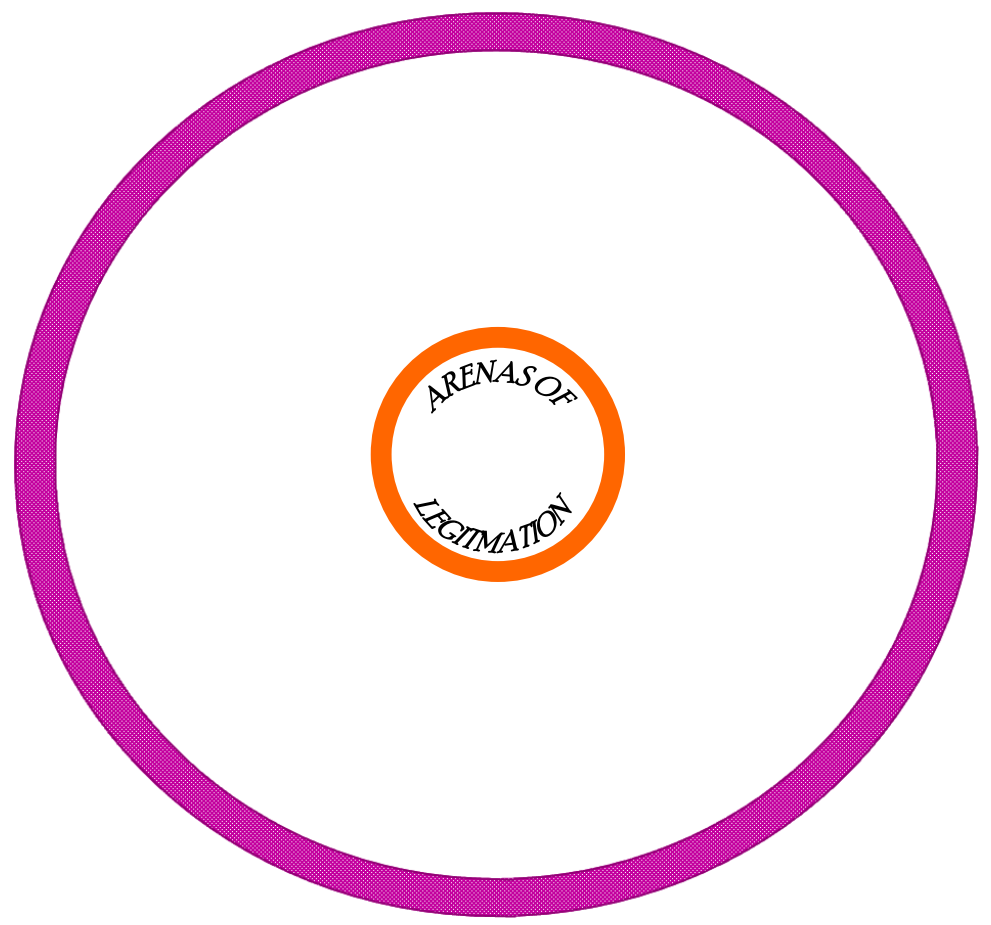

At the centre of this relational space are the institutions and social systems that both produce and shape the latent patterns of interest and struggle. Focusing on these social sites, the second task is to establish and explore the arenas of legitimation that exists at the heart of the social field. Important here is to locate institutional, cultural or social sites that form a dominant positon within the field's boundary. Representing a unifying habitus of strategies, constraints and opportunities, the cultural production of knowledge that takes place within these social systems produce a distinct hierarchy of 
exclusivity and legitimation that establishes a cultural acceptance of the 'rules of the game' (Bourdieu, 1977). Within the field of finance, this relates specifically to the social frame of the bank. It is here where the normative assumptions and practices of finance are crystallised and embodied to create a dominating culture of financial life. Rather than representing a particular or singular bank, this is a relative and relational construct that represents the primary site of dominance, cultural reproduction and change (Bourdieu \& Wacquant, 1992). The interactions that take place within this arena of struggle and legitimation establish the prescribed set of exchange relations that press on experience to produce action (Wacquant \& Bourdieu, 1993). Establishing a tacit acceptance of the 'rules of the game' that govern the field, the framework of the bank can be seen to, in Bourdieu's (1984) terms, uphold a dominant system of knowledge production in the struggle for distinction.

The importance of the bank in relation to the field of finance lies in how it represents the fulcrum through which the flow and speed of market interaction is channelled. It is here where the normative assumptions and practices of finance are crystallised and embodied to create a dominating culture of financial life. While each bank has its own institutional culture and participants often spoke of the contrasting experiences of working for a hierarchical American structures versus a conservative European models, the task at hand is to attempt to cut through some of these internal differences to focus on the commonalities the collectively produce a universal market 'way of being'. In the first instance, each of these are heavily fortified institutions that represents, on the one hand, a legitimate images of security and trust that are a prerequisite for financial institutions. More prominently, on the 


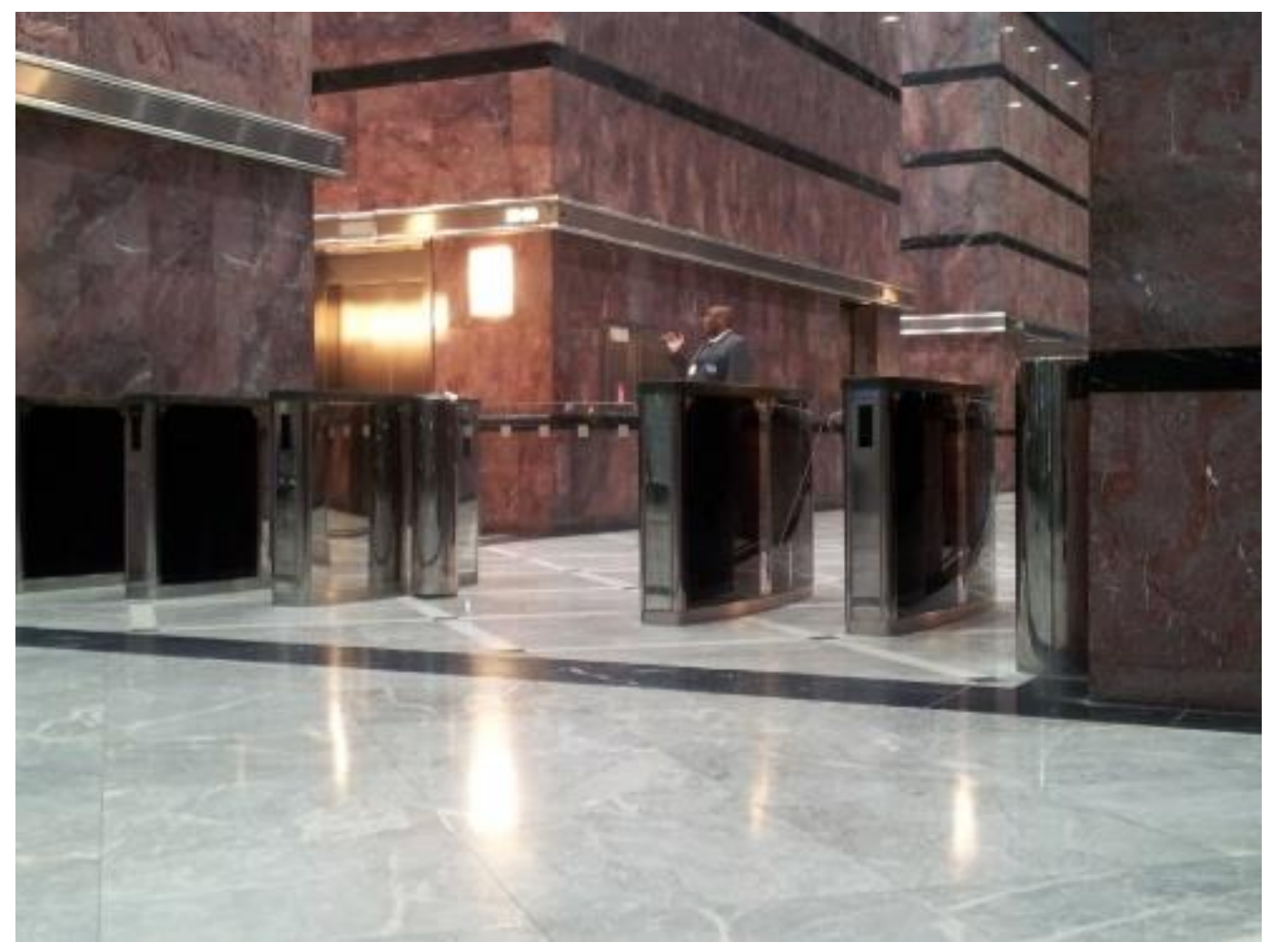

Figure 75: Line of electronic security

other hand, this security and surveillance is an exercise in the language of symbolic violence, power and domination. As such, the physical organisation of the bank imbibes a claustrophobic and watchful feeling. A complex web of CCTV cameras electronically patrol the immediate vicinity outside the bank, monitoring the movements permeating around its walls. Revolving glass doors allow only intermittent entry into the bank itself, marshalled by a security guard on either side, commonly dressed as a concierge. The final frontier, as shown in Figure 7, is the line of electronic barriers that demarcate experience between the 'quasi-public' space of the lobby and the inner depths of the bank itself. Notably, it is here that the lens of the camera stops. By bounding the framework of the bank, as well as restricting the movement of certain individuals within its parameters, a distinct market reality is constructed - one which, in Bourdieu's (1985) terms, is formed on the basis of a collective unity, selfserving rule systems and ideological practices. 
Beyond the security, located in vast open-plan office environments, the abstractions of the market mechanism are turned into a solid, tangible object of financial reality. Within these offices, commonly taking up the entire width and breadth of the building, economic actors grouped together in teams interact with one another, through the technological and topographical landscape, to create a dominant system of market action. On each desk sit up to eight computer screens that both recreate and map the complex speed and flow of market action. Detailing specific movements and trajectories of various invested products and services, what is created is a wide angle, ideographic representation of the ever changing fluctuations of market activity. Alongside the visual creation of the market are various text and audio control systems that create a 'multi-firm chat room' that brings together the speed and flow of the market making process. Through the proliferation of these technological instruments of exchange, traders, sales and brokers can buy, sell and swap various financial services and products to create a system of market action on a global scale. In one physical proximity the entire speed and flow of the global market system is recreated and reduced to a tangible system of graphs and numbers mapped out on a screen. At the same time, as Zaloom (2006) notes, the instruments of technology that sit on each desk allow the reach of the individual economic agent to extend out of this bounded space and touch upon almost every part of an increasingly global marketplace. Bringing the market, as a tangible object of financial life, into being, the perpetual struggle that takes place within the framework of the bank, in the manner of Wacquant and Bourdieu (1993), serves to establish the rules of legitimation that, in turn, come to govern the field. Engendering a common affinity, an axis of unity is generated which establishes a dominant vision - one which is organised around a collective adherence to the market itself. Sanctifying and recreating, in a very real and tangible sense, the abstract nature of the market, the framework of the bank engenders a common adherence to a distinct market reality. 


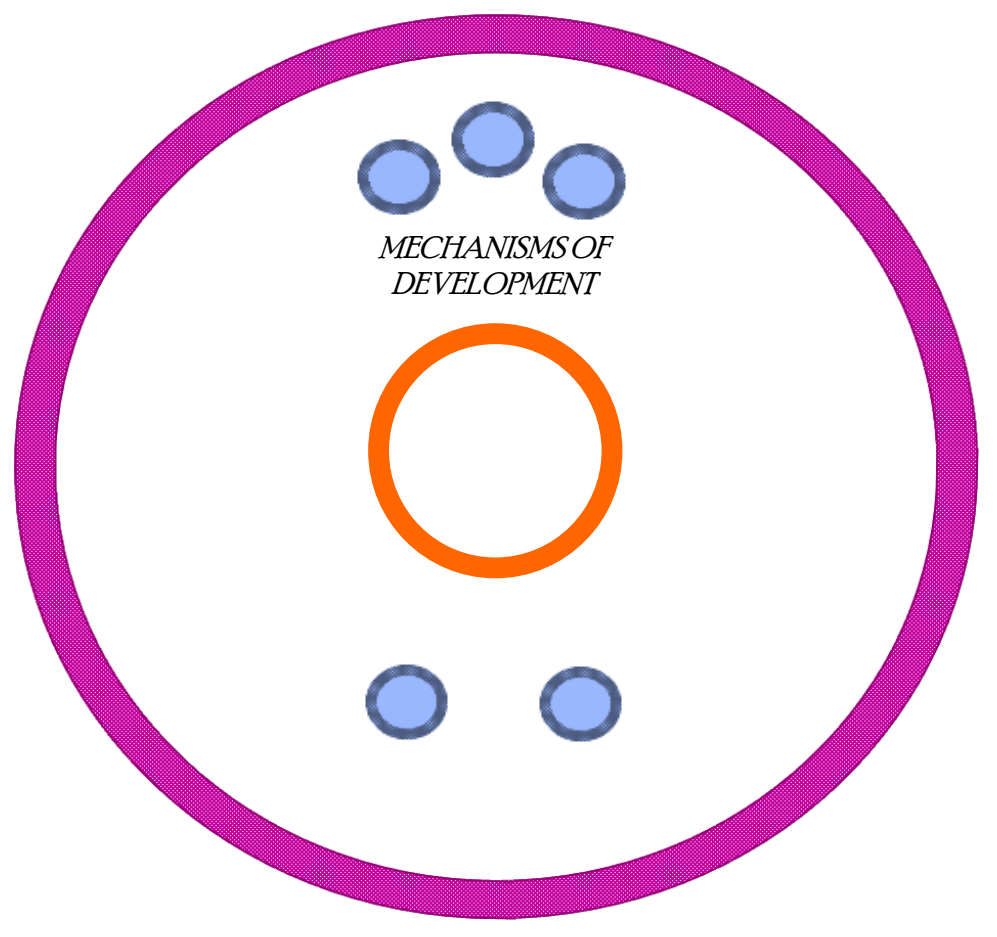

A defining feature of Bourdieu's field analysis is how the cultural field, as a bounded social space with a central mechanism of legitimation and struggle, progressively develops to gain greater autonomy from surrounding factors (Swartz, 1997). In this respect, the City and the field of financial life can be seen to have developed a distinct set of organisational, market based interests that produce an ideologically driven version of reality that shapes perception and produces practice (Bourdieu \& Wacquant, 1992). Part of this production of a distinct social reality that characterises any social field relates to the mechanisms and tools of development; these are the vital props and social strategies that are used to create the enacted reality of life. Beyond the architectural framework of the bank is a tight collection of bars, cafés, restaurants, shops and other services which run through the spatial environment of the City, sustaining it as a hub of social activity. In analysing these spaces, it is possible to chart the mechanisms and tools of development that both sustains and reproduces a distinct social reality - a function that represents the third step in this analysis. It is within this spatial and material environment that individuals and groups draw on the competing cultural, symbolic and social resources in order to maintain and enhance their positions in the social order as well as exercise their 


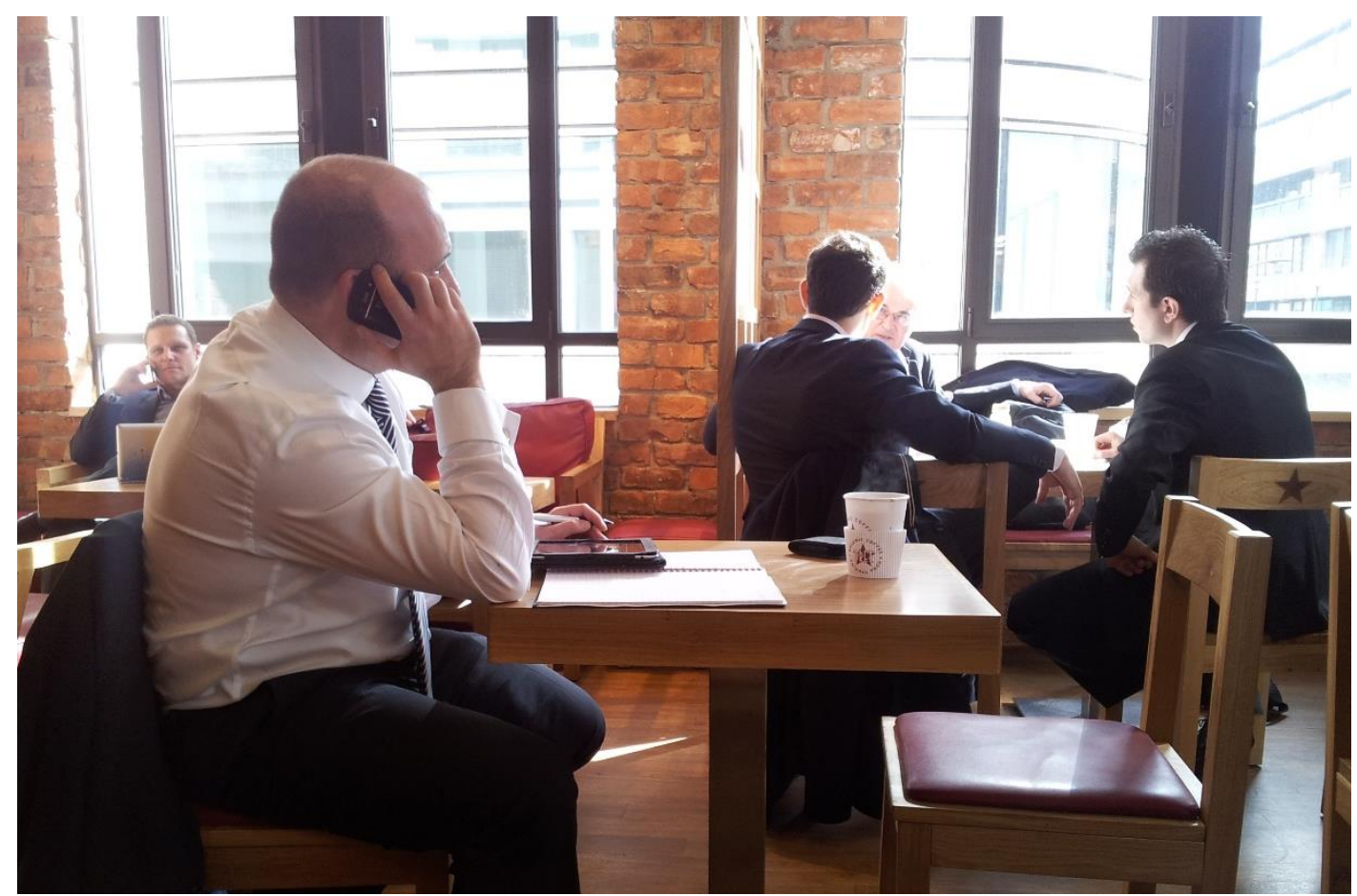

Figure 8: A morning in a café on King William Street

own power as a social relation that press onto the material structure of the field to continue the reproduction of a market based social reality (Bourdieu, 1996; Bourdieu \& Wacquant, 1992). The importance of these sites, in the manner of Goffman (1963) and Loftland, et al. (2004), is how they intersect with other (principally subordinated) social fields, populated by the heterogeneity of service, construction and profession workers who each, in their own way, support the City's primary roles as a key hub of financial activity.

Throughout the City there are a vast selection of coffee shops, noodle and take away outlets, restaurants and bars that provide the cash rich but time poor finance workers with their daily needs. In creating a bounded field of financial life, these services are imperative to maintain, in Bourdieu's (1991) terms, a relative degree of autonomy by providing the services for day-to-day economic action. As a site of action, economic actors compete in an informal struggle of power, drawing on the symbolic language of dominance and control. During the morning hours, the bulk of the social activity is drawn towards cafés and are characterised by a controlling confidence and authority. These are spaces 
generally populated by the elder, more senior economic agents. As depicted in Figure 8, groups gather in the morning to escape from the pressures of the office to catch up on reading or discuss group strategies. Each encased in their designer suits, white shirts and sipping their bottled water or coffee, they are brought together through a prism of privilege and a firm belief in themselves as successful, market making individuals. Here, the atmosphere is heavy with the weight of intense and careful negotiations. There is a common discipline with little 'tough talking' or 'posturing'. This is not a place to say something rash which you will later regret. Like a game of chess, the interactions taking place in this environment are organised around a subtle battle for control and authority as each individual engages intellectually to secure a favourable outcome. Within this environment the grind of competition is replaced by a slow struggle for control, the building of alliances and the strategic battle of wits against the movement of the market in the search for profit. This is a purely intellectual pursuit as each individual agent strives to embody the discipline, complexity and intellectualism of market action.

By way of contrast, the heavily populated pubs and bars of the City reflect the speed and the aggression of the market. These spaces are characterised by quick wit, coarse language and heavy drinking. Competition here is rife. Accents of public school boys clash with the 'Essex' traders as each individual seeks to establish 'bragging' rights - be it the biggest deal, sharpest play or even an exceptional loss. Whereas the 'elder statesmen' in the cafés compete in a slow game of intellectual negotiation, the younger workers in the pubs are engaged in a fast-paced game of aggressive posturing and display of physical endurance through heavy drinking and chain-smoking. Through the crowds forming outside, such as shown in Figure 9, Big Issue sellers break the collective display of wealth and success while tourists and other passers-by are instantly recognisable by their less than clinical appearance. Within these spaces smoking and drinking becomes a social prop to access crucial 


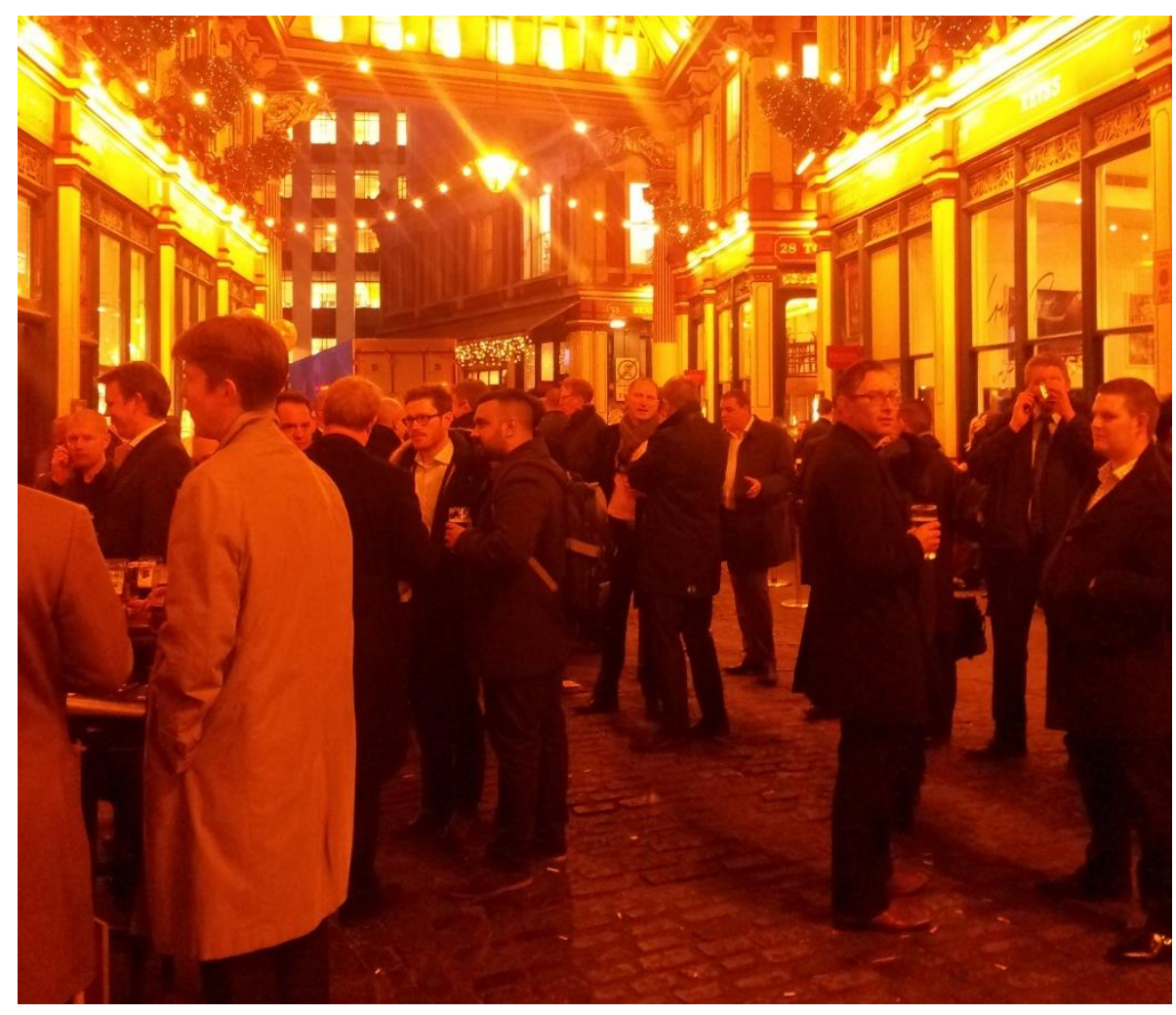

Figure 9: After work at the popular Leadenhall Market

networks that lead to a more secure and advantageous position within the field. This drinking culture that carries on long into the night is turned into a collective display of discipline and adherence to the cultural demands of the market mechanism. Speaking to Simon, a financial analyst in his forties who has spent his entire career in the City, he explains how:

'You would think that drinking seven, eight, nine pints of Guinness and then tequila shots until two o'clock in the morning, being ill and then getting up the next morning and falling asleep in meetings would be the frowned upon but it is actually not, you get a pat on the back. Whereas, if I go in sober and I haven't drunk they are like, 'where were you?' Not part of the team.'

This ability to sustain this level of drinking yet still be at your desk in the morning becomes transformed into a display of discipline as well as a common bond of trust. During these long evenings networks are formed, allegiances drawn and battles waged. It can also be read as a method of exclusion and common affinity. Many of the women who partook in this study complained about how they felt that they must make a choice between focusing on work and socialising later into the evening or sacrifice future work prospects by prioritising family and home life. As a common display in being interested, 
rare and sought after (Bourdieu, 1977), the ability to sustain this assault on the body turns what appears to be mindless drinking into interested social calculation. In turn, the culture of drinking is expressed as a resource of power that forges a collective affinity around manifestations of discipline and sacrifice to the market mechanism that can be used to both include and exclude alike.

vi. The Field of Power: Imposing a dominant vision of social reality

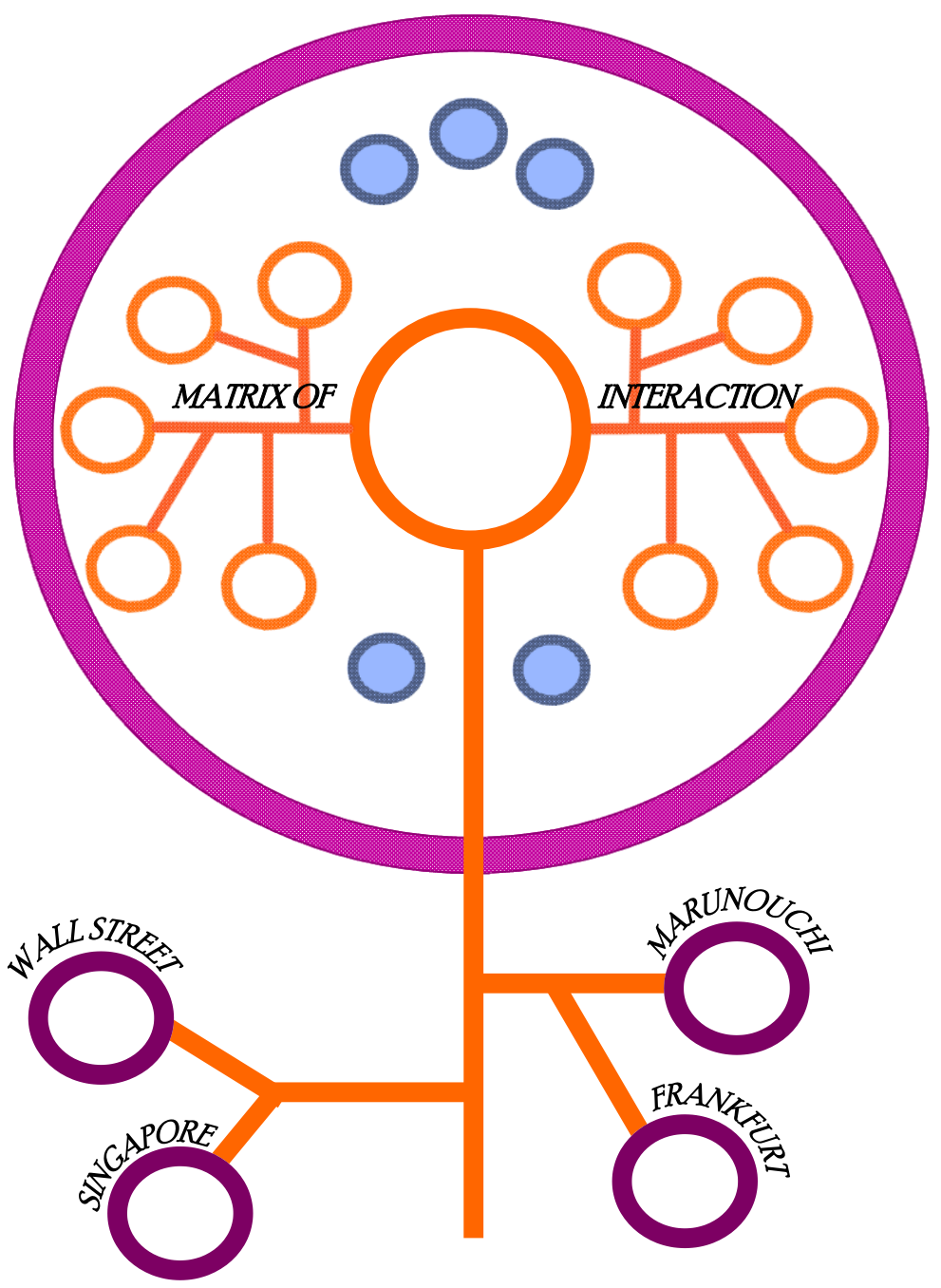

The final task of establishing a visualisation of the field relates to situating the established social reality within a broader system of power relations and interlocking fields. Running through the framework of the City of London are lines of social and technological interaction that form a matrix of market interaction, linking up financial institutions within the City of London as well as expanding out to touch 
upon other key hubs of market action in the global market place. These lines of interaction bring together individual agents and institutions through a matrix of spatial, corporeal and technological market action as well as convey the character of the social field of finance as a web of cultural interaction and exchange. On one level, these lines of social and technological interaction complete the spatial framework, mapping out the 'interrelationships' which exist formally through the institutional instruments of technology and physical proximity that connect economic agents within different financial service institutions to one another as well as, informally, through the social infrastructure within the City. However, at the same time they represent the structures and power struggles engaged within the field frame a matrix of dispositions which organise perception of a financial reality and, ultimately, establish a unifying 'principle of coherence', or cultural habitus (Bourdieu \& Wacquant, 1992). As a relative, ideographic construction, the network of market interaction that runs the through spatial, corporeal and technological channels that link each of these institutions and economic actors together, as well as integrated the City into a broader, global, system of market interaction and exchange. The organising interests of the market mechanism that runs through the day-to-day actions and common expectations of economic life establish an internal and self-defined logic of what is considered inherently 'true' or 'good'. In this manner, the aegis of the market not only brings into life a particular form of self-interested individual of economic life but, also, establishes a legitimising framework of action, common expectations and interest that is pressed onto other social fields that collectively makeup social life.

Within this framework, the market is turned from an object of financial reality and into a structuring formation of power that impinges on the thoughts, actions and material landscape of those who actively engage with it. For one trader on the bond market, Marcus, this meant that the market is seen as an imperative 'truth' in relation to which he must orient his own actions and perceptions: 
'As the market falls you need to know when to get off the escalator. It is not always that simple, you may be hanging onto a poor deal, waiting and anticipating the market to pick up. But each day your stock is literally falling. It is a little bit like death by a thousand cuts. After a while it becomes natural, second nature, like breathing. You feel the market, anticipate its movements, learn when to hold tight and when to get off.'

For Marcus, the market manifests as a barometer of success that determines what is considered 'normal' and 'expected' action. It is the market that acts as a form of 'meta-field' that operates, much like Bourdieu's (1992) field of power, as an organising principle of struggle and differentiation throughout all fields of financial life, structuring the terms of success and failure in the process. Be it throughout shareholder value or the fluctuations of bond values, the market comes to structure action and produce an essential reality that presses on the City of London as well as beyond.

Relating to the field of power, the market, as an economic and political orthodoxy, is universally imposed and unanimously accepted both within the field of finance and across society to the point that it is beyond the reach of discussion and contestation (Bourdieu, 2001). Within the City of London, operating through this matrix of social interaction, is the prolonged and continual work of an intellectually endowed financial workforce who concentrate and organise market action through enterprises of production, dissemination and intervention. Upheld is the imperative of short-term profit that, with complete disregard for issues of moral, ethical or social value, acts as the practical purpose for the entire system. Moreover, as Bourdieu (2001, p. 12) argues, the dominant actors in this game are dominated by the field of power and market interest (manifesting most pressingly through the rule of profit) to function as an infernal machine without subject and which imposes its will on the minds, bodies and organisational interests throughout. It is a structure that determines and endows cultural and economic capital on those who successful embody the essence of the fast paced, competitive intellectualism and discipline of market life. It is a lived in cultural framework of 
experience that, in Smithsimon's (2010) terms, establishes the City of London as a financial 'citadel' of a global 'market society'.

\section{vii. Conclusion}

In creating an ideographic representation of the City of London and the embedded framework of market action within, it is possible to better understand how economic agents operate within the surrounding topographical, technological and social environment of the City of London to actively (re)produce a culturally embedded and dominant system of market behaviour. In particular, this relates to how the 'social topology' of financial life generates a collective unity and enshrined market disposition. Leading to an expected and performative 'way of being', the material and social construction of the field of finance leads to the emergence of a situated and strategic framework of action from which the 'truths' and taken for granted assumptions which establish the normative practices of market life can be seen to emerge (Bourdieu, 1984). However, the real contribution of this paper is in unpacking a four-step analysis of the Bourdieu's field to further enhance understandings of social systems within urban studies. Specifically this relates to focusing, in turn, on firstly, the construction and maintenance of the field's boundary; secondly, the arenas of legitimation that exists at the heart of the social field; thirdly, the mechanisms and tools of development that both sustains and reproduces a distinct social reality; and finally, situating this social reality within a broader, 'horizontal' field of power that presses on all social fields. In unpacking these steps, through the sociology of Bourdieu, this paper highlights how it is possible to make visible the structural formations of cultural, political and economic dominance that is inherent within the social development of place. Illustrating the commanding order and stratification of power that is crucial to the development of urban analysis, what emerges is a relational systems of understanding in which individuals and groups, as part of their day-to-day lives, compete to secure intellectual legitimation and cultural dominance that impinges on the material and social landscape. 
As Swartz (1997, p. 142) argues, establishing a relational field of action in this manner is only the first step in unpacking the Bourdieu's theoretical and empirical framework. Taking this further, it is important to identify the objective system of relations and positions occupied by individuals or groups as they compete for legitimation through an internally recognised system of economic and cultural capital and, with it, cultural distinction. From here it is then possible to analyse a cultural habitus that is brought by agents to their respective positions and the social trajectory they pursue within the field of struggle. Taken together, this is a multi-layered and overlapping framework of analysis. It entwines the structural and institutional formation of the field (along with the dominant field of power) with the embodied legitimation of cultural capital that brings economic agents together through their individual dispositions to pursue a social trajectory within the field of finance. In particular, the focus on the layered analysis of the field allows for a critical unpacking of its spatial and social organisation, the legitimate and sought after resources that shape intense competition before analysing the legitimate and taken for granted assumptions that produce a system of a positive (ennobling) or negative (stigmatising) set of cultural practices - each of which underline a relation understanding of social deviance and financial life. 


\section{Bibliography}

Bourdieu, P., 1977. Outline of a Theory of Practice. Cambridge: Cambridge University Press.

Bourdieu, P., 1980. Questions de Sociologie. Paris: Editions de Minuit.

Bourdieu, P., 1984. Distinction: A Social Critique of the Judgement of Taste. London: Routledge.

Bourdieu, P., 1985. The Social Space and the Genesis of Groups. Theory and Society, Volume 14, pp. 723-744.

Bourdieu, P., 1991. Le Champ Littéraire. Actes de la Recherche en Sciences Sociales, 89(September), pp. 4-46.

Bourdieu, P., 1996. The State Nobility: Elite Schools in the Field of Power. Cambridge: Polity Press.

Bourdieu, P., 2001. Firing Back: Against the Tyranny of the Market 2. London: The New Press.

Bourdieu, P. \& Wacquant, L., 1992. An Invitation to Reflexive Sociology. Chicago: University of Chicago Press.

Brewer, J., 2000. Ethnography. Buckingham: Open University Press.

Cetina, K. \& Bruegger, U., 2002. Global Microstructures: The Virtual Societies of Financial Markets. American Journal of Sociology, 107(4), pp. 905-950.

Goffman, E., 1963. Behavior in Public Places: Notes on the Social Organisation of Gatherings. New York: Free Press.

Harquinet, L., Savage, M. \& Callier, L., 2012. Elaborating Bourdieu's Field Analysis in Urban Studies: Cultural Dymanics in Brussels. Urban Geography, 33(4), pp. 508-529.

Helleiner, E., 2011. The Evolution of the International Monetary and Financial System. In: J. Ravenhill, ed. Global Political Economy. 3rd ed. Oxford: Oxford University Press, pp. 215-243.

Kynaston, D., 2002. The City of London Volume IV: A Club No More 1945-2000. London: Pimlico.

Loftland, J., Snow, D., Anderson, L. \& Loftlan, L., 2004. Analyzing Social Settings: A Guide to Qualitative Observation and Analysis. 4th ed. Belmont, CA: Wadsworth Publishing.

ONS, 2014. Business Register and Employment Services, s.I.: October.

O'Reilly, K., 2005. Ethnographic Methods. London: Routledge. 
Pauly, L., 2011. The Political Economy of the Financial Crisis. In: J. Ravenhill, ed. Global Political Economy. 3rd ed. Oxford: Oxford University Press, pp. 215-272.

Sack, R., 1993. The Power of Place and Space. Geographical Review, 83(3), pp. 326-329.

Sack, R., 1999. A Sketch of a Geographic Theory of Morality. Annals of the Associations of American Geographers, 89(1), pp. 26-44.

Sassen, S., 2005. The Embeddedness of Electronic Markets: The Case of Global Capital Markets. In: K. Cetina \& A. Preda, eds. The Sociology of Financial Markets. Oxford: Oxford University Press, pp. 17-37.

Shaxson, N., 2011. Treasure Islands: Tax Havens and the Men who Stole the World. London: Vintage Books.

Smithsimon, G., 2010. Inside the Empire: Ethnography of a Global Citadel in New York. Urban Studies, 47(4), pp. 699-724.

Swartz, D., 1997. Culture and Power: The Sociology of Pierre Bourdieu. Chicago: University of Chicago Press.

Therborn, G., 2013. "Global Cities", World Power, and the G20 Capital Cities. In: Cities and Crisis: New Critical Urban Theory. London: SAGE, pp. 51-82.

Wacquant, L. \& Bourdieu, P., 1993. From Ruling Class to Field Power: An Interview with Pierre Bourdieu on La noblesse d'Etat. Theory, Culture and Society, 10(3), pp. 19-44.

Webb, B. \& Webb, S., 1932. Methods of Social Study. London: Longmans Green.

Zaloom, C., 2006. Out of the Pits: Traders and Technology from Chicago to London. Chigaco: University of Chicago Press. 